\title{
A Classification of Micrococci and Staphylococci Based on Physiological and Biochemical Tests
}

\author{
By A. C. BAIRD-PARKER \\ Unilever Research Laboratory, Colworth House, Sharnbrook, Bedford
}

(Received 18 June 1962)

\begin{abstract}
SUMMARY
1250 Gram-positive and catalase-positive cocci were isolated from bacon, pig and human skin and dust, and their morphology, physiology and biochemical characters examined. The genera Staphylococcus, Micrococcus and Sarcina were recognized. Staphylococci were distinguished by their ability to form acid from glucose anaerobically and sarcinas by the formation of cubical packets. 570 isolates could be placed in the genus Staphylococcus, 677 in the genus Micrococcus and 3 in the genus Sarcina. Six subgroups were recognized within the genus Staphylococcus and seven within the genus Micrococcus. The relationship of these subgroups to previously defined genera and species is discussed.
\end{abstract}

\section{INTRODUCTION}

Many classifications of the Gram-positive and catalase-positive cocci have been suggested. Some authors place all organisms in a single group or genus, others into two or more genera. The classification of Shaw, Stitt \& Cowan (1951) proposed combining all organisms in the genus Staphylococcus. Evidence for the more traditional approach of recognizing several genera was obtained by Evans, Bradford \& Niven (1955) and Hill (1959). The latter concluded from computer data that members of Shaw, Stitt \& Cowan's genus Staphylococcus were better placed into two genera. The genus Staphylococcus was retained for those organisms which formed acid from glucose aerobically but did not possess a pink pigment. The genus Micrococcus was re-introduced to contain the pink-pigmented organisms and those types unable to form acid from glucose. Evans et al. (1955) suggested a different classification based on the observation of Evans (1947, 1948) that coagulase-positive staphylococci, together with some coagulase-negative, Gram-positive and catalase-positive cocci, could grow and form acid from glucose anaerobically. They proposed that the two genera Staphylococcus and Micrococcus should be recognized and separated on the ability of the former genus togrow and to produce acid anaerobically. This classification forms the basis of that followed in the most recent edition of Bergey's Manual (1957). It was criticized by Thatcher \& Simon (1957) who found that all their isolates formed similar amounts of acid both aerobically and anaerobically, and more recently by Garvie, Higgs \& Neave (1961) who reported finding coagulase-positive staphylococci which were unable to attack glucose anaerobically. I have been unable to confirm either of these observations and my results based on a study of 1250 isolates agree with those of Evans et al. (1955). The object of the present work was to classify the aerobic, Gram-positive and catalase-positive cocci found on bacon, human and pig surfaces, and dust. 


\section{METHODS}

1250 isolates of Gram-positive and catalase-positive cocci were freshly isolated; 920 of these isolates were from bacon. The bacon was macerated aseptically and plated on tryptone yeast glucose salt agar (TYGSA) containing $6 \%(\mathrm{w} / \mathrm{v})$ sodium chloride (Cavett, 1962). Colonies from plates incubated at $30^{\circ}$ for 3 days were subcultured on to nutrient agar plates and tested for catalase by using $3 \%(w / v)$ hydrogen peroxide (Society of American Bacteriologists, 1957). Single colonies of catalasepositive organisms were picked on to slopes of yeast glucose agar (YGA) of the following composition $(\%, w / v)$ : glucose, 0.5 ; Evans peptone, $0.5 ; \mathrm{Na}_{2} \mathrm{HPO}_{4}, 0.5 ;$ Difco yeast extract, $0.5 ;$ Lab-Lemco, 0.5 ; agar 1.5. These cultures were incubated for $24 \mathrm{hr}$. at $30^{\circ}$ and then stored at $5^{\circ}$ until required. Coagulase-positive staphylococci were isolated on the selective and diagnostic medium of Baird-Parker (1962). 152 isolates were from armpits and hands of 24 volunteers. The skin was subjected to a standardized washing procedure to remove transient organisms (Hurst, Stuttard \& Woodroffe, 1960). Organisms recovered in the wash-water after this procedure were cultivated on blood agar. 70 isolates were from 24 pig trotters. Isolations were made from ground-up skin, previously washed by the same procedure as used for making isolations from human skin. 108 isolates were from household dust. Plates of TYGSA were exposed to air for 30 to $60 \mathrm{~min}$.; after incubation for 3 days at $30^{\circ}$, catalasepositive colonies were picked on to nutrient agar plates.

Morphology. Smears were made from nutrient agar plates incubated for $24 \mathrm{hr}$. at $30^{\circ}$ and stained by Gram's method. The Gram reaction, size and arrangement of organisms was noted. Hanging drop preparations of $24 \mathrm{hr}$. nutrient broth cultures were used for motility tests and for further observations on morphology. The appearance of growth in nutrient broth was noted. Features of 3-day colonies $\left(30^{\circ}\right)$ on nutrient agar were determined by using a $\times 50$ binocular plate microscope. Pigmentation of colonies was noted at the same time and compared where possible with the pigment of similarly aged colonies on milk agar.

Physiological test methods. Experiments were so arranged that the isolates were subcultured as little as possible before testing. Organisms stored at $5^{\circ}$ were revived by plating on YGA. Single colonies were further plated on to nutrient agar followed by picking into nutrient broth. These cultures were incubated overnight at $30^{\circ}$ and used to inoculate the test media outlined in the following sections. Analar or Difco products were used unless otherwise stated, and bacteriological grade 'sugars' were used throughout; also unless otherwise stated the $\mathrm{pH}$ value of media was adjusted to between $\mathrm{pH} 7 \cdot 2$ and $7 \cdot 4$. Media were sterilized at $120^{\circ}$ for $15 \mathrm{~min}$. Liquid media were dispensed ( $5 \mathrm{ml}$.) in $1 \mathrm{oz}$. screw-capped McCartney bottles. Tests on solid media were made in Petri dishes, 6 isolates being radially streaked per plate. After inoculation, liquid media were incubated for 14 days at $30^{\circ}$ before testing. Solid media were also incubated at $30^{\circ}$ and read daily up to a maximum of 7 days.

Phosphatase. Ability to produce phosphatase was tested in the following medium $(\%, \mathrm{w} / \mathrm{v})$; Evans peptone, 0.5; Lab-Lemco, 0.5; NaCl, 0.5; agar, 1.5 . To $100 \mathrm{ml}$. the molten basal medium $\left(45^{\circ}\right)$ was added $1 \mathrm{ml}$. of a $1.0 \%$ Seitz-filtered solution of phenolphthalein diphosphate (sodium salt; L. Light, Colnbrook, England; Barber \& Kuper, 1951). Inoculated plates were incubated for 3-5 days at $30^{\circ}$. It should be noted that this procedure differs from the original one used by Barber \& Kuper for 


\section{Classification of Micrococci and Staphylococci}

detecting coagulase-positive staphylococci; they incubated for only $18 \mathrm{hr}$. at $37^{\circ}$. The release of free phenolphthalein was detected using a drop of $0 \cdot 880 \mathrm{sp}$. gr. ammonia placed in the lid of each Petri dish. Phosphatase-producing colonies turned deep pink immediately on exposure to ammonia vapours.

Coagulase. The production of free coagulase (Duthie, 1954) was tested by the method of Fisk (Mackie \& McCartney, 1960). Difco dried rabbit plasma was reconstituted and $0.3 \mathrm{ml}$. added to $0.1 \mathrm{ml}$. of an overnight culture in heart infusion broth. Tubes were incubated at $37^{\circ}$ and read at 1 and $3 \mathrm{hr}$. and after standing overnight at room temperature. Any degree of coagulation of the plasma was recorded positive.

Acid production from carbohydrates. Ability to produce acid from glucose aerobically and/or anaerobically was tested by Hugh \& Leifson's (1953) method with the following medium $(\%, \mathrm{w} / \mathrm{v}): \mathrm{NH}_{4} \mathrm{H}_{2} \mathrm{PO}_{4}, 0.1 ; \mathrm{KCl}, 0.02 ; \mathrm{MgSO}_{4} .7 \mathrm{H}_{2} \mathrm{O}, 0.02 ;$ yeast extract, 0.1 ; bromocresol purple, 0.004 ; agar $0.2 ; \mathrm{pH} 7 \cdot 0$. The medium was sterilized in $90 \mathrm{ml}$. amounts and $10 \mathrm{ml}$. of a $10 \%$ (w/v) Seitz-filtered solution of glucose added to the molten base (about $45^{\circ}$ ) immediately before use. It was dispensed aseptically into sterile 6 in. $\times \frac{1}{2}$ in. test tubes which were two-thirds full. The medium was steamed for $15 \mathrm{~min}$. to drive off dissolved oxygen and kept at $5^{\circ}$ until set. Duplicate tubes were stab inoculated throughout their length with a heavy inoculum from nutrient agar plates. After inoculations the surface of one tube of each duplicate was covered with a 1-2 in. layer of sterile liquid paraffin. After incubation for 5-10 days the tubes were examined for acid production. The production of acid from carbohydrates other than glucose was detected on plates of the same mineral salt yeast extraction medium as used for glucose, except that the agar concentration was increased from 0.2 to $1.5 \%(\mathrm{w} / \mathrm{v})$. Seitz filtered 5 to $10 \%$ solutions of the carbohydrates under test were added to the molten base to give final concentrations of $0.25-0.5 \%$. After a preliminary trial with 28 carbohydrates the following 14 were selected for use: L-arabinose, cellobiose, dextrin, galactose, $\alpha$-methyl-Dglucoside, glycerol, inositol, lactose, maltose, mannitol, raffinose, rhamnose, salicin, xylose.

Acetoin production and final $\mathrm{pH}$ value in glucose broth. Medium (\%, w/v): Tryptone, 1.0; Lab-Lemco, 0.3 ; yeast extract, $0 \cdot 1$; glucose, $2 \cdot 0$. The $\mathrm{pH}$ value of the inoculated medium was determined electrometrically after incubation for 14 days. The presence of acetoin was detected by the method of Barritt (1936) and in some cultures by Batty-Smith's (1941) method.

Aesculin hydrolysis. Medium (\%,w/v): Tryptone, 1.0; Lab-Lemco, 0.3; yeast extract, $0.1 ; \mathrm{Na}_{2} \mathrm{HPO}_{4}, 0.5$; aesculin, $0 \cdot 5$. The release of the phenolic aglycone was detected by adding $0.5 \mathrm{ml}$. of a $1 \%$ solution of ferric ammonium citrate, allowing to stand at room temperature for 1-2 min., and then examining for blackening of the medium and loss of fluorescence (Barnett, Ingram \& Swain, 1956).

Starch hydrolysis. Medium $(\%, \mathrm{w} / \mathrm{v})$ : Tryptone, $1 \cdot 0$; yeast extract, $0 \cdot 1$; LabLemco, 0.3; starch, 0.02; agar, 1.5 (modified from Eckford's, 1927, medium). Starch hydrolysis was detected by flooding with Lugol's iodine.

Milk agar. The following basal medium was made up to four fifths of the finally required volume and dispensed in $80 \mathrm{ml}$. amounts $(\%, \mathrm{w} / \mathrm{v})$ : Tryptone, 1.0; LabLemco, $0 \cdot 3$; yeast extract, $0 \cdot 1 ; \mathrm{Na}_{2} \mathrm{HPO}_{4}, 0.5$; agar, 1.5 . Low fat milk was obtained by standing milk for $3 \mathrm{hr}$. in a $45^{\circ}$ incubator and skimming off the free fat. The milk 
was adjusted to $\mathrm{pH} 7 \cdot 0$ and dispensed in $20 \mathrm{ml}$. amounts. It was sterilized by autoclaving at $115^{\circ}$ for $10 \mathrm{~min}$.; $20 \mathrm{ml}$. of warmed milk was added to $80 \mathrm{ml}$. of the basal medium before use. Inoculated plates were examined daily for clearing around the colonies. After 5 days, plates were flooded with acid mercuric chloride (Frazier, 1926) to distinguish between true proteolysis and clearing of the milk due to solubilization of the milk protein by alkaline end products of metabolism (Hastings, 1904).

Egg yolk agar. The following basal medium was prepared $(\%, \mathrm{w} / \mathrm{v}):$ Evans peptone, 0.5 ; Lab-Lemco, $0.5 ; \mathrm{NaCl}, 0.5$; agar, 1.5. Oxoid concentrated egg yolk emulsion was added to the molten base to give a final concentration of $5 \%(\mathrm{v} / \mathrm{v})$. Plates were read as for the milk agar plates.

Gelatin agar $(\%, \mathrm{w} / \mathrm{v})$ : Tryptone, $1 \cdot 0$; yeast extract, $0 \cdot 1$; Lab-Lemco, $0 \cdot 3$; gelatin, 0.4; agar, 1.5. Gelatin hydrolysis was detected by the method of Frazier (1926).

Ammonia production in arginine broth $(\%, \mathrm{w} / \mathrm{v})$ : Tryptone, $1 \cdot 0$; yeast extract, $0 \cdot 1$; Lab-Lemco, $0.3 ; \mathrm{Na}_{2} \mathrm{HPO}_{4}, \mathbf{0 . 5}$; L-arginine $\mathrm{HCl}, \mathbf{0 . 3}$. Ammonia was detected by removing $1 \mathrm{ml}$. of culture supernatant fluid and adding to it $0.5 \mathrm{ml}$. Nessler's reagent.

Breakdown of other amino acids. Washed suspensions of organisms were used for detecting ammonia production from arginine, asparagine, cysteine, glycine, methionine, and serine. Decarboxylation of glutamic acid, lysine and arginine was tested by the methods of Moeller (1955) and Carlquist (1956). Anaerobic breakdown of arginine was determined by the method of Thornley (1960).

Hydrogen sulphide production. The decomposition of specific organic and inorganic compounds with $\mathrm{H}_{2} \mathrm{~S}$ formation (Olitzki, 1954) was investigated by using washed suspensions of organisms and the following substrates: cysteine, methionine, thioglycollate, thiosulphate, sulphite.

Hippurate hydrolysis. Medium $(\%, \mathrm{w} / \mathrm{v})$ : Tryptone, 1.0; Lab-Lemco, 0.3; yeast extract, $0 \cdot 1$; glucose, $0 \cdot 1 ; \mathrm{Na}_{2} \mathrm{HPO}_{4}, 0.5$; sodium hippurate, $1 \cdot 0$. It was sterilized by autoclaving at $115^{\circ}$ for $10 \mathrm{~min}$. The release of benzoate was tested by adding $1.5 \mathrm{ml}$. of $50 \%(\mathrm{v} / \mathrm{v})$ conc. sulphuric acid to $1 \mathrm{ml}$. of culture supernatant fluid and standing at room temperature for $4 \mathrm{hr}$. Free benzoic acid was precipitated as fine crystals (Ayers \& Rupp, 1922).

Nitrate reduction. Medium (\%, w/v): Tryptone, 1.0; Lab-Lemco, 0.3; yeast extract, 0.1 ; glucose, $0 \cdot 1 ; \mathrm{Na}_{2} \mathrm{HPO}_{4}, 0.5$; sodium nitrate, 0.02 . Reduction of nitrate was determined by adding $1 \mathrm{ml}$. each of Griess-Ilosvay's reagents to the culture fluid (Recommended method of Society of American Bacteriologists, 1957). Results were read after standing for about 5 min. Reduction of nitrate beyond nitrite was tested by adding a knife tip of zinc dust. Production of ammonia from nitrite was determined by using washed suspensions of organisms incubated for $6 \mathrm{hr}$. at $30^{\circ}$ in $2 \times 10^{-5} \mathrm{M}$-sodium nitrite buffered at $\mathrm{pH} 7.5$ with $\mathrm{M} / 15$ sodium cacodylate.

Lipolysis. Ability to hydrolyse butter and lard with the release of free fatty acids was tested by using the Jones \& Richards' (1952) medium. Care was taken to emulsify the fats by vigorous shaking before pouring the plates. When the medium was almost set it was poured into cooled plates $\left(5^{\circ}\right)$ in order to prevent separation of the fats. The hydrolysis of Tweens with the release of free fatty acids was tested in Sierra's (1957) medium; Tweens 20, 40, 60 and 80 (Honeywill-Atlas Ltd.) were used as substrates. 
Ammonium phosphate utilization. The medium used was that published by Hucker (1924). Difco Nobel agar was used to solidify the medium. Slopes were inoculated with organisms from mineral-salt yeast-extract agar in order to minimize the transfer of organic material. Inoculated slopes were examined weekly for growth and acid production; they were incubated for 1 month.

Growth in media containing sodium chloride. Ability to grow in a peptone medium containing no added sodium chloride, or 5 or $15 \%(w / v)$ sodium chloride was tested by using the media and methods suggested by Pohja (1960).

Growth at $10^{\circ}$ and $45^{\circ}$. Tests were carried out in stirred water baths with an accuracy of $\pm \mathbf{0 \cdot 2 5 ^ { \circ }}$. Yeast-extract glucose broth was brought to the temperature of incubation and inoculated with about $0.5 \mathrm{ml}$. of an overnight nutrient broth culture. Inoculated bottles were incubated submerged to their necks.

Recording of results. The results obtained were recorded on Paramount brand punch cards in order to compare characters of the isolates. All positive characters, weak and strong, were punched out; the strength of the reaction was noted on the cards. The isolates were sorted into groups, taking into account all their characters.

Experiments on variation of physiological characters. To avoid defining groups of isolates on unstable characters, attempts were made to cause variation in a collection of 6 isolates when frequently subcultured. Two strains each of Shaw et al. (1951) subgroups 1, 2 and 3 were resuscitated from 12-14 months old, freeze-dried cultures and plated on YGA. Single colonies were picked and replated. The process of picking and replating was repeated five times, and from the final platings 6-8 colonies of each organism were inoculated into nutrient broth. The broths were incubated overnight and used to inoculate the tests outlined in the previous sections of this paper. All tests were read after incubation for 7 days. This procedure was repeated four times, the first culture of the preceding series being used as the mother culture for the next series.

\section{RESULTS}

\section{Morphology}

The 1250 isolates were Gram-positive and catalase-positive cocci which divided in more than one plane, either regularly to form tetrads or cubical packets, or irregularly to form different sizes of loose or compact clusters. The ability to form cubical packets appeared to be a stable character produced both in broth and on solid media. The formation of loose or compact clusters showed considerable variation on different media, and tetrads were formed by many strains which otherwise grew as irregular clusters. Although the organisms were Gram-positive in young culture this character was frequently lost in cultures older than $48 \mathrm{hr}$. The organisms were often slightly elongated, and divided by septa formed at right angles to their long axis; short chains of 3-4 cocci were commonly present. Motile strains were not found among these isolates.

Colonies were mainly convex $(\mathbf{0} \cdot 5-2 \cdot 0 \mathrm{~mm}$. diam.) with an entire edge and a smooth or slightly granular surface sometimes with radial striations. Some organisms when first isolated formed hard, irregular colonies clinging to the surface of the agar, but this property was unstable and lost by most isolates on subculture. Organisms undergoing regular division and forming cubical packets usually possessed 
characteristic large granular matt colonies. Colonies were white, yellow or orange pigmented. Yellow- or orange-pigmented isolates often gave rise to white variants which when tested were physiologically identical to their parent types.

The appearance of the growth in broth was variable. The anaerobic glucose utilizers (staphylococci) grew usually as an easily suspendable fine sediment. Sometimes the culture fluid became turbid with a tendency to form a ring of growth at the surface of the medium in cultures older than $48 \mathrm{hr}$. In contrast, the growth in broth of those organisms which utilized glucose only aerobically (micrococci) mostly gave a mucoid sediment which was difficult to disperse; the culture fluid above these sediments remained clear. Some organisms grew as a granular sediment, often with small colonies developing on the sides of the bottles.

\section{Physiology}

Phosphatase. After incubation at $30^{\circ}$ for 3 days all coagulase-positive isolates were strongly phosphatase-positive together with $\mathbf{3 7 8}$ coagulase-negative isolates which utilized glucose anaerobically and 4 isolates which utilized glucose only aerobically. Weak activity was recorded from 4 isolates which did not utilize glucose and from 2 which attacked glucose only aerobically.

Coagulase. Twenty-two isolates were positive after incubation in the presence of rabbit plasma for $3 \mathrm{hr}$; 2 isolates were only positive after leaving for a further $18 \mathrm{hr}$. at room temperature.

Acid from carbohydrates. Isolates showed three types of activity in the breakdown of glucose in the mineral-salt yeast-extract medium used for the Hugh \& Leifson test: (1) acid throughout the open and sealed tubes; (2) acid at the surface and upper part of the open tube, no acid in depth of sealed tube; (3) no acid, i.e. no change in the bromocresol purple indicator, in either the open or the sealed tube. All coagulasepositive isolates together with $\mathbf{5 4 6}$ other organisms grew and formed acid throughout the open and sealed tubes; of the remainder, 669 isolates formed acid at the surface and upper part of the open tubes and sometimes slight acid at the surface of the sealed tubes. The location of acid production coincided with growth. Growth was most rapid in the open tubes and when acid production occurred in the depth of the agar it was accompanied by growth. Acid production in the depth of the sealed tube was considered to take place under anaerobic conditions and organisms which showed this activity will be referred to in this paper as anaerobic glucose utilizers. Pohja (1960) found that many of his Gram-positive and catalase-positive cocci formed acid weakly anaerobically, i.e. $\mathrm{pH}>\mathbf{5} \cdot 7$. These would not be detected with bromocresol purple as an indicator of acid production.

Many isolates utilized a wide range of carbohydrates besides glucose. These carbohydrates were incorporated in an agar medium since it was found, in agreement with Hill (1959), that a plate test gave clear-cut results. The carbohydrates most frequently attacked by the anaerobic glucose utilizers were: galactose, glycerol, lactose, maltose, mannitol. Those isolates which utilized glucose aerobically but not anaerobically also frequently formed acid from L-arabinose, cellobiose, inositol, rhamnose and xylose. Some organisms also attacked $\alpha$-methyl D-glucoside, dextrin, raffinose, salicin and starch; the breakdown of starch was usually weak. Daily readings of plates was necessary since acid from some carbohydrates, particularly L-arabinose, was often present only transiently, with subsequent reversion to alkaline conditions. 
Acid from mannitol was produced both aerobically and anaerobically by those coagulase-positive staphylococci able to attack this sugar alcohol. In contrast, only 2 out of $\mathbf{4 0}$ coagulase-negative anaerobic glucose utilizers which formed acid from mannitol aerobically were able to do so anaerobically. These results agree with those of Evans (1948) and Dr D. A. A. Mossel (1962).

Acetoin and final $p H$ value in glucose broth. Acetoin was produced mainly by the anaerobic glucose utilizers; its production usually was accompanied by a terminal $\mathrm{pH}$ value in $2 \%$ glucose broth below $\mathrm{pH} 5.5$. Identical results were obtained for 100 isolates when the presence of acetoin was tested for by the method of Barritt (1936) and the more sensitive method of Batty-Smith (1941). A larger number of organisms was positive in the phosphate-free $2 \%$ glucose medium used in the present work than in the glucose phosphate medium commonly used for the Voges-Proskauer (VP) test (Mackie \& McCartney, 1960). Similar results were reported by Abd-El-Malek \& Gibson (1948) and Shaw et al. (1951). It was necessary to incubate for at least 14 days to avoid missing late acetoin producers.

Aesculin. Aesculin was mainly hydrolysed by those isolates which were acetoinnegative and utilized glucose only aerobically.

Effects in milk agar, egg-yolk agar and gelatin agar. Most isolates which utilized glucose anaerobically caused clearing of milk in milk agar plates; many of these also cleared egg yolk and hydrolysed gelatin. These activities were generally weak or absent from the other isolates, although some packet formers were actively gelatinolytic. Clearing of milk and egg yolk was due mainly to solubilization of the proteins by alkaline end products of metabolism since treatment with acid mercuric chloride (Frazier, 1926) resulted in a decrease or disappearance of the clearing.

Decomposition of amino acids and hydrogen sulphide production. Most isolates produced ammonia when grown in arginine broth. All coagulase-positive isolates formed ammonia from arginine anaerobically in Thornley's (1960) medium, whereas only 5 out of 24 coagulase-negative isolates which formed ammonia aerobically were also positive anaerobically. Washed suspensions of $\mathbf{1 2}$ of 20 isolates formed ammonia from arginine, 15 of these also formed small amounts of ammonia from serine; no ammonia was detected from asparagine, cysteine, glycine or methionine. Glutamic acid, lysine and threonine were not deaminated. Traces of hydrogen sulphide were formed from thiosulphate (7 of 20 isolates) and from cysteine (9 of 20 isolates) but not from methionine, thio-glycollate nor sulphite.

Hippurate was hydrolysed by most isolates.

Nitrate reduction. Nitrate was reduced by most isolates; gas was not detected. Many isolates which utilized glucose anaerobically reduced nitrate to ammonia, whereas most of those isolates which utilized glucose only aerobically or did not attack glucose, reduced nitrate to nitrite.

Lipolysis, and hydrolysis of Tweens. Lard, butter and Tweens were hydrolysed by most of the isolates which utilized glucose anaerobically. Tweens 20,40 and 60 were more frequently attacked than Tween 80 . The remaining isolates generally did not attack these substrates except for some phosphatase and acetoin producers, and some of the organisms which did not form acid from carbohydrates.

Ammonium phosphate utilization. Eleven of the isolates which utilized glucose anaerobically grew weakly on the ammonium phosphate medium and formed small amounts of acid after incubation for 21-28 days. Forty isolates which formed acid 
only aerobically from glucose, grew and produced acid between 7 and 21 days. Several isolates grew weakly on the medium but failed to form acid.

Growth in the presence of $5 \%$ and $15 \%$ sodium chloride. All isolates grew in Pohja's (1960) medium without added sodium chloride with exception of 2 coagulasenegative phosphatase-positive isolates. However, growth of many of the anaerobic glucose utilizers was weak. All isolates grew in the presence of $5 \%$ sodium chloride and most in the presence of $15 \%$.

Growth at 10 and $45^{\circ}$. With the exception of 5 isolates all the coagulase-negative organisms which formed acid from glucose anaerobically did not grow at $10^{\circ}$. Growth at $45^{\circ}$ was a more variable character but most of the isolates grew at this temperature. In contrast, all but 21 of the isolates which formed acid only aerobically grew at $10^{\circ}$, and with the exception of 38 isolates, did not grow at $45^{\circ}$. Most of the coagulase-positive isolates grew at 10 and $45^{\circ}$ as also did some of the packet formers and isolates which did not attack glucose.

\section{Examination of instability of some physiological characters}

Six cultures of Shaw et al. (1951) subgroups 1, 2 and 3, which were freeze-dried and examined about 1 year later, showed only minor changes in physiological reactions on retesting. None of the strongly positive characters was lost although one subgroup 3 isolate had lost the ability to attack xylose and hydrolyse casein. However, both of these characters were weak when the isolate was tested before freeze-drying. One isolate apparently gained the character to form acid weakly from galactose. Further apparent changes were noted when the strains were subcultured frequently and tested over a period of 1 month. Series of colonies picked from the subgroup 1 and 2 strains reduced nitrate to nitrite or a more reduced end product, and showed change in ability to form detectable ammonia when grown in arginine broth. Some of these colonies also apparently became able to produce acetoin. This was associated with a terminal $\mathrm{pH}$ greater than 5.5 in $2 \%$ glucose broth; cultures having a final $\mathrm{pH}$ of 4.5 to $5 \cdot 0$ contained acetoin. The acetoin-negative cultures became positive when retested with the incubation time extended from 7 to 14 days. Similarly, variations in end-products of nitrate reduction and the production of ammonia from arginine were eliminated by longer incubation. Thus tests on end products of glucose, arginine and nitrate metabolism should be performed after 14 days incubation to avoid negative results due to weak activities

\section{Grouping of isolates}

The isolates examined could be divided into 3 main groups. Group 1 contains $\mathbf{5 7 0}$ isolates which utilize glucose anaerobically; it corresponds to the genus Staphylococcus as defined by Evans in Bergey's Manual (1957). Members of group 2 (677 isolates) only utilized glucose aerobically or not at all; this group corresponds to the genus Micrococcus as defined by Bergey's Manual (1957). Group 3 contains 3 packet-forming isolates corresponding to the genus Sarcina Goodsir.

Group 1 (Staphylococcus Rosenbach emend. Evans). It was possible to recognize 6 subgroups within this group. The main characters of these are shown in Table 1; complete characters together with those of groups 2 and 3 are tabulated in Table 3.

Group 2 (Micrococcus Cohn emend. Evans). Members of this group could be divided 
in to 7 subgroups on their physiological characters. Their main characters are shown in Table 2, complete characters in Table 3.

Group 3 (Sarcina Goodsir). Too few isolates were obtained to recognize subgroups. Complete characters of the $\mathbf{3}$ isolates are listed in Table $\mathbf{3}$.

Table 1. Main characters of subgroups within Group 1 (Staphylococcus Rosenbach emend. Evans)

\begin{tabular}{|c|c|c|c|c|c|c|}
\hline \multirow[b]{2}{*}{ Characteristic } & \multicolumn{6}{|c|}{ Subgroups } \\
\hline & I & II & III & IV & $\mathbf{V}$ & VI \\
\hline Coagulase & + & - & - & - & - & - \\
\hline Phosphatase & + & + & + & - & - & - \\
\hline Mannitol (aerobic) & $\begin{array}{c}+ \\
\text { (usually) }\end{array}$ & - & - & - & - & + \\
\hline Mannitol (anaerobic) & $\begin{array}{c}+ \\
\text { (usually) }\end{array}$ & - & - & - & - & (usually) \\
\hline Acetoin & + & + & - & + & + & + \\
\hline Lactose & $\stackrel{+}{+} \stackrel{+}{\text { (usually) }}$ & $\begin{array}{c}+ \\
\text { (usually) }\end{array}$ & $\mathrm{v}$ & - & + & $\mathbf{v}$ \\
\hline Maltose & + & + & - & $\mathbf{v}$ & + & $\mathbf{v}$ \\
\hline Growth at $10^{\circ}$ & $\begin{array}{c}+ \\
\text { (usually) }\end{array}$ & - & - & - & - & (usually) \\
\hline No. of isolates & 24 & 354 & 24 & 53 & 19 & 96 \\
\hline
\end{tabular}

Table 2. Main characters of subgroups within Group 2 (Micrococcus Cohn emend. Evans)

\begin{tabular}{|c|c|c|c|c|c|c|c|}
\hline \multirow[b]{2}{*}{ Characteristic } & \multicolumn{7}{|c|}{ Subgroups } \\
\hline & 1 & 2 & 3 & 4 & $\mathbf{5}$ & 6 & 7 \\
\hline $\begin{array}{l}\text { Acid from glucose } \\
\text { (aerobic) }\end{array}$ & + & + & + & + & + & + & - \\
\hline Phosphatase & - & - & - & - & - & + & - \\
\hline Acetoin & + & + & + & + & - & - & - \\
\hline $\begin{array}{l}\text { Average end } \mathrm{pH} \\
\text { value in } 2 \% \\
\text { w/v glucose } \\
\text { broth }\end{array}$ & $4 \cdot 6$ & $5 \cdot 1$ & $5 \cdot 0$ & $5 \cdot 2$ & $5 \cdot 5$ & $5 \cdot 3$ & $6 \cdot 5$ \\
\hline Arabinose & - & - & - & + & $\mathbf{v}$ & + & - \\
\hline Lactose & - & + & $\mathbf{v}$ & + & $\begin{array}{c}+ \\
\text { (usually) }\end{array}$ & + & - \\
\hline Maltose & $\mathbf{v}$ & + & $\begin{array}{c}+ \\
\text { (usually) }\end{array}$ & + & $\begin{array}{c}+ \\
\text { (usually) }\end{array}$ & + & - \\
\hline Mannitol & - & - & + & + & $\begin{array}{c}+ \\
\text { (usually) }\end{array}$ & + & - \\
\hline Lipolysis & $\mathbf{v}$ & + & + & - & (usually) & $\begin{array}{c}+ \\
\text { (usually) }\end{array}$ & $\mathbf{v}$ \\
\hline $\begin{array}{l}\text { Tween } \\
\text { hydrolysis }\end{array}$ & $\begin{array}{c}- \\
\text { (usually) }\end{array}$ & - & $\mathbf{v}$ & - & - & + & $\mathbf{v}$ \\
\hline Growth at $10^{\circ}$ & (usually) & $\stackrel{+}{+}$ & $\begin{array}{c}+ \\
\text { (usually) }\end{array}$ & + & $\stackrel{+}{+}$ & + & $\stackrel{+}{+}$ \\
\hline No. of isolates & 17 & 8 & 75 & 19 & 544 & 4 & 10 \\
\hline
\end{tabular}




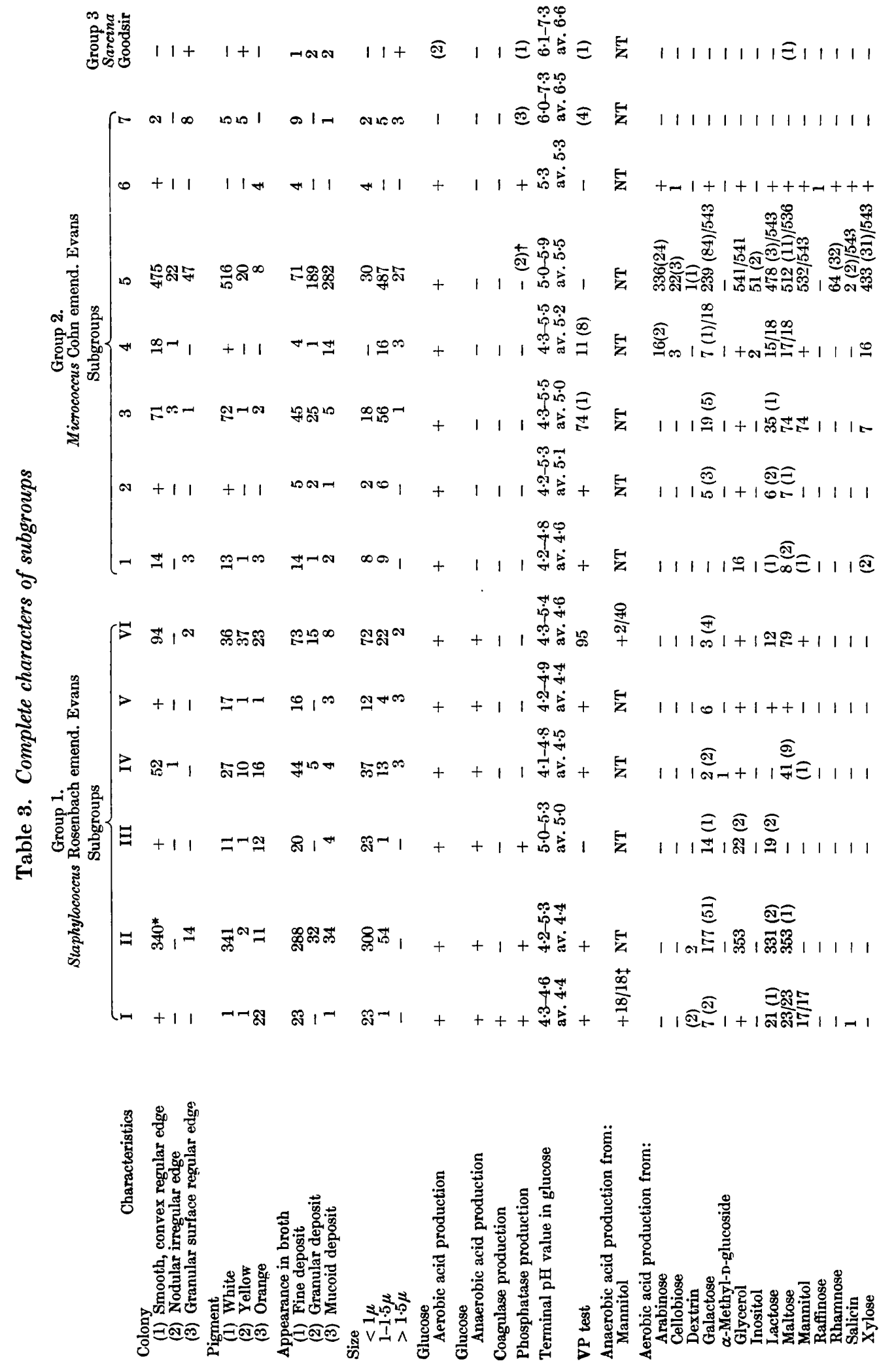




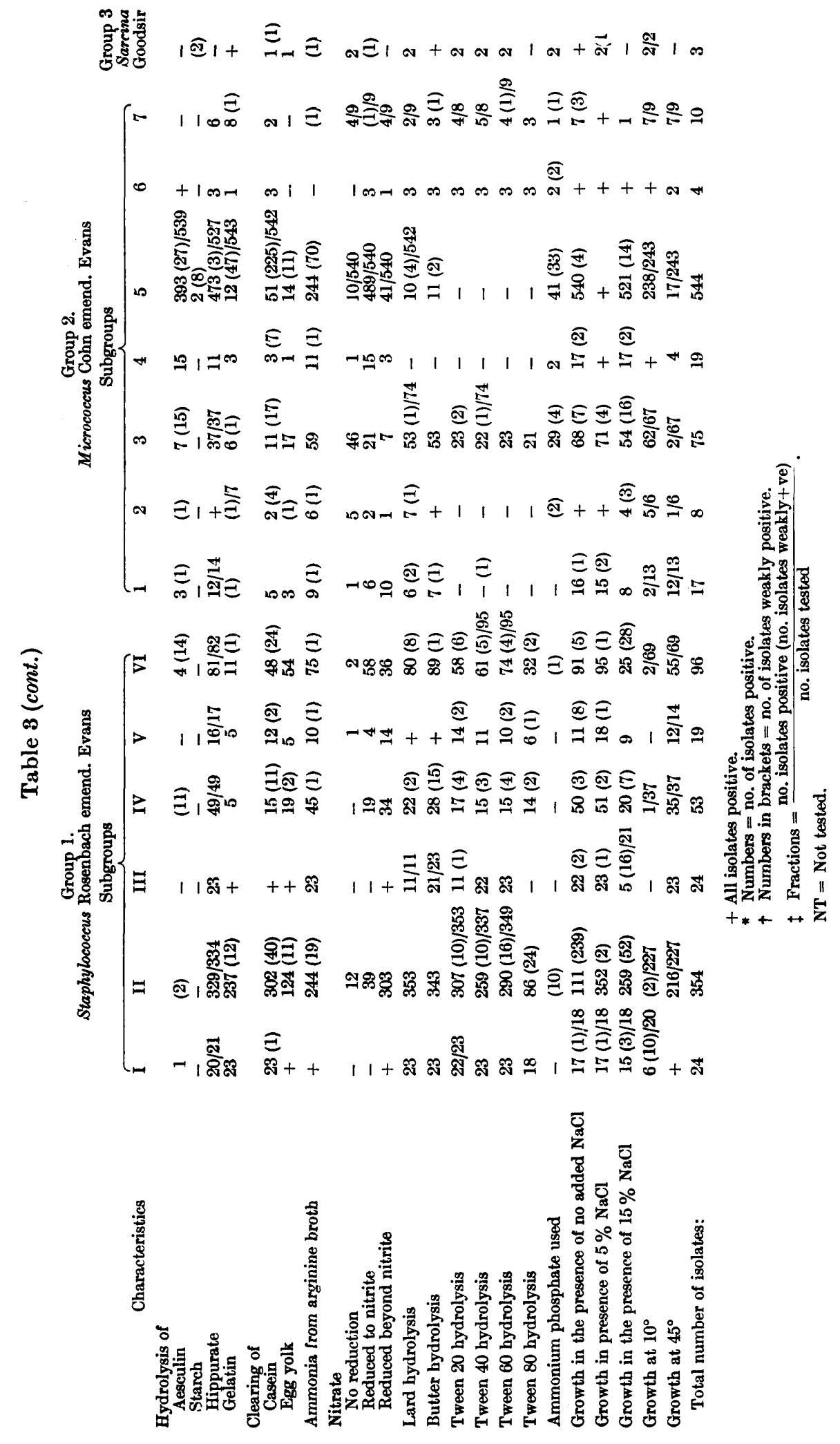




\section{DISCUSSION}

The Gram-positive and catalase-positive cocci isolated from bacon, human and pig skin, and dust can be divided into 3 main groups similar to the genera Staphylococcus, Micrococcus and Sarcina as defined in Bergey's Manual (1957). The genera are closely related and form a series of morphological and physiological types ranging from the biochemically active small staphylococci to the relatively inactive large sarcinas. Evidence was obtained, in agreement with the proposals of Evans $e t$ al. (1955), that two genera, Staphylococcus and Micrococcus, could be separated by the ability of Staphylococcus to grow and form acid from glucose anaerobically. The 3 isolates which formed packets were morphologically distinct from these two genera although physiologically related to Micrococcus. There appeared to be no reasonable grounds for ignoring the genus Sarcina, as suggested by Shaw et al. (1951), since the formation of packets appeared to be stable. However, it could be possible to confuse the true packet formers with some of the tetrad-forming micrococci unless hanging drop preparations were examined under phase contrast. Following these observations those organisms which grew as tetrads were placed in the genus Micrococcus. They were mostly members of subgroup 7 .

Hill (1959) suggested that all non-pink pigmented Gram-positive and catalasepositive cocci which produced acid from glucose should be placed in the genus Staphylococcus. This suggestion was made from a study of only 49 strains analysed according to the Adansonian classification as suggested by Sneath (1957). It sets broad limits to the genus Staphylococcus and results in classifying the unrelated saccharolytic sarcinas in the same genus as the coagulase-positive staphylococci; the non-saccharolytic sarcinas would be placed in the genus Micrococcus. Pohja (1960), who also used the Adansonian classification, proposed to limit the genus Staphylococcus to Shaw, Stitt \& Cowan's two species, Staphylococcus aureus and S. saprophyticus, the latter being defined to contain Gram-positive and catalase-positive cocci which formed acetoin from glucose. If this classification were accepted my subgroup III staphylococci, which are acetoin-negative but ferment glucose anaerobically (Table 3), would be placed in a Micrococcus subgroup. This classification would disregard the main distinguishing character between staphylococci and micrococci, which is the fermentative or oxidative utilization of glucose.

Separation of staphylococci from micrococci on anaerobic glucose utilization, i.e. ability to grow and produce detectable acid in the depth of sealed tubes with bromocresol purple as an indicator, results in the delimitation of a group of organisms which are morphologically and physiologically similar to Staphylococcus aureus. The latter is accepted as type species of the genus Staphylococcus (Judicial Commission of the International Committee of Bacteriological Nomenclature and Taxonomy; Stockholm, 1958). It appears reasonable to suggest, therefore, that since anaerobic glucose utilization, under the conditions mentioned, separates a group of organisms which are closely related to the type species of the genus Staphylococcus, this is a better method of separating staphylococci from micrococci than the divisions proposed by Hill or Pohja. Two strains of $S$. aureus (NCDO 1236, 1238) were described by Garvie et al. (1961) as not forming acid from glucose anaerobically; but both organisms did so when tested by the Hugh \& Leifson test as described in the present paper. Some convergence between the proposed genera can be seen from the results listed in 


\section{Classification of Micrococci and Staphylococci}

Table 3. For example, some Staphylococcus subgroup IV isolates were distinguished from those of Micrococcus subgroup 1 solely on anaerobic glucose utilization. The presence of intermediate types between genera and species must be expected if evolutionary concepts are to be accepted (Gibson, 1955; Lysenko, 1961); convergencies can be found between almost every genus in bacteriology.

\section{Proposed classification}

Six subgroups were recognized within the genus Staphylococcus. Members of subgroup I produce coagulase and belong to the species Staphylococcus aureus as defined by Shaw et al. (1951). They also produce phosphatase and are able usually to form acid from mannitol, aerobically and anaerobically. Members of subgroup II although phosphatase-positive are well separated from those of subgroup I by not forming coagulase or acid from mannitol. These organisms are found frequently on human and pig surfaces and in household dust. They are also found in large numbers in bacon stored at $30^{\circ}$ (Cavett, 1962). Closely related to subgroups II are members of subgroups $\mathrm{V}$ which are phosphatase-negative. They are found in similar habitats to subgroup II members. Subgroup III organisms are found frequently on pig skin but were not isolated from human skin or household dust. This subgroup although phosphatase-positive and mannitol-negative is distinguished from subgroup II by not forming acetoin from glucose or acid from maltose. Subgroup IV members are unable to produce phosphatase and although acetoin-positive, attack only a limited range of carbohydrates. They were isolated from skin surfaces and from bacon. In subgroup VI are placed those phosphatase-negative staphylococci which form acid from mannitol, usually only aerobically; within this subgroup 3 types can be distinguished on ability to attack maltose and lactose (see definitions).

Seven subgroups were recognized within the genus Micrococcus. As previously mentioned subgroup 1 members are similar to Staphylococcus subgroup IV but are unable to form acid from glucose anaerobically when tested by the described method. Members of this subgroup were isolated mainly from dust and bacon. Subgroup 2 is separated from subgroup 1 by forming acid from lactose. They usually have a terminal $\mathrm{pH}$ value $>5.0$ in glucose broth and usually grow at $10^{\circ}$; they were mostly isolated from bacon. Subgroup 3 organisms occur mainly in dust and vacuum-packed bacon. They are closely related to members of subgroup 2 but are mannitol-positive; 3 types can be separated on ability to hydrolyse lard and Tweens, and to grow and form acid in a medium containing glucose and ammonium dihydrogen phosphate as sole carbon and nitrogen sources (see definitions). Subgroups 4 and $\mathbf{5}$ are closely related, being distinguished only by the formation of acetoin. Both of these subgroups are found frequently in bacon and subgroup 5 is the predominant Micrococcus subgroup found in this product. Subgroup 6 is a small subgroup found on pig skin. The ability of this subgroup to produce phosphatase together with its other characters clearly separates it from the other subgroups (see Table 3). Subgroup 7 contains a heterogeneous collection of organisms which produce little or no acid from glucose and no detectable acid from other carbohydrates. Members of this subgroup were isolated from all sources studied. 


\section{Relationship of proposed classification to previous classifications}

Staphylococcus aureus constitutes a well-defined species when defined on ability to form coagulase (Evans \& Niven, 1950; Shaw et al. 1951); it corresponds to my subgroup I. The recognition of other species of staphylococci and micrococci is controversial. Shaw et al. (1951) said that their classification 'like all other classifications of cocci is arbitrary and artificial'. Hill (1959) concluded that $S$. saprophyticus of Shaw et al. contained a natural group of organisms corresponding to $S$. epidermidis (Bergey's Manual, 1957). My results do not support this conclusion. First, S. epidermidis, as defined, is always mannitol-negative whilst $S$. saprophyticus, to quote Hill, is often positive. Secondly, it does not appear that organisms classified in $S$. saprophyticus constitute a natural group. According to my grouping the following subgroups would belong to $S$. saprophyticus: Staphylococcus subgroups II, IV, V and VI and Micrococcus subgroups 1, 2, 3 and 4. The two most dissimilar subgroups, namely Staphylococcus subgroup II and Micrococcus subgroup 4, show a greater diversity of characters than between many members of Shaw, Stitt \& Cowan's $S$. lactis and $S$. saprophyticus. For example, Micrococcus subgroup 4 (S. saprophyticus, Shaw et al.) is more closely related to Micrococcus subgroup 5 ( $S$. lactis, Shaw et al.) than either Staphylococcus subgroup II and Micrococcus subgroup 4 are related to each other. In agreement with Hill (1959) my results show that $S$. lactis is not a natural group; this species contains my Staphylococcus subgroup III and Micrococcus subgroups 5 and 6 , organisms which are very different (Table 3).

Organisms corresponding to Staphylococcus roseus of Shaw et al. were not isolated from the habitats studied. However, examination of NCTC strains of this species indicated that it would be better named Micrococcus roseus as suggested by Hill (1959).

Staphylococcus afermentans of Shaw et al. (1951) was not recognized as a species name by Hill (1959) and he did not regard it as a valid group. This conclusion agrees with the present work. Members of the Micrococcus subgroup 7 are most closely related to $S$. afermentans. However, this subgroup contains a miscellaneous collection of morphological and physiological types which possess the common character of forming little or no detectable acid from carbohydrates. Too few isolates have been studied to suggest better division of this subgroup.

Definitions of species of staphylococci and micrococci in editions of Bergey's Manual have been criticized by Abd-El-Malek \& Gibson (1948) and by Pohja (1960). I agree with many of their criticisms, particularly regarding the difficulty in trying to type isolates according to the somewhat contradictory characters given in the Bergey's Manual. It was impossible to relate with any degree of certainty my Micrococcus subgroups to species of micrococci recognized in the Bergey's Manual, although the Staphylococcus subgroups could be mostly placed in one or the other of the two species recognized in the 7th edition. Staphylococcus aureus is similar to my subgroup I and subgroups II, III, IV and V belong to $S$. epidermidis (Winslow and Winslow) Evans. The characters of subgroup VI fit none of the species recognized in Bergey's Manual although the two members of this subgroup which utilize mannitol anaerobically would apparently be placed with $S$. aureus. The physiological characters of the tetrad formers fitted none of the species of Gaffkya recognized in Bergey's Manual. Two of the Sarcina isolates corresponded to the species Sarcina lutea. 


\section{NOMENCLATURE}

Staphylococcus aureus appears to be the only species about which there is general agreement as to its validity; most of the other so-called species of staphylococci and micrococci are not true species. It is suggested, therefore, that at present species names other than $S$. aureus should not be used and that non-pathogenic staphylococci and micrococci should be classified into subgroups along the lines proposed in the present paper. To define more clearly the subgroups recognized in this work I have followed the procedure used by Shaw et al. (1951) namely, to separate essential characters of the proposed subgroups from the usual or variable characters.

\section{Definitions}

\section{Group 1. Staphylococcus Rosenbach emend. Evans}

General characters. Regular, small celled $(0 \cdot 5-1 \cdot 5 \mu)$ Gram-positive and catalasepositive cocci which form acid anaerobically from glucose and grow as compact or loose clusters. Usually acetoin is produced as an end product of glucose metabolism with a terminal $\mathrm{pH}$ value less than $\mathbf{5} .0$ in $2 \%$ glucose broth. Acid is formed usually from glycerol, lactose and maltose. Mannitol is utilized aerobically and anaerobically by coagulase-producing strains and usually only aerobically by other organisms which attack mannitol. Acid is not usually formed from $\alpha$-methyl-D-glucoside, arabinose, dextrin, inositol, raffinose, rhamnose, salicin or xylose. Aesculin and starch are not usually hydrolysed. Many organisms are phosphatase-positive. Proteins, hippurate, fats and Tweens are usually actively hydrolysed and ammonia produced in arginine broth. Nitrate is usually reduced beyond nitrite. Ammonium phosphate is not utilized as sole nitrogen source. Growth can usually occur in the presence of $15 \%$ sodium chloride and at $45^{\circ}$. Usually no growth at $10^{\circ}$ with the exception of some coagulase producers.

Subgroup I: (Staphylococcus aureus) essential characters. Coagulase-positive and phosphatase-positive; usually form acid from mannitol, aerobically and anaerobically.

Other characters. Acid from glycerol and maltose, usually from galactose and lactose, and sometimes from dextrin and salicin; acetoin produced in glucose broth. Nitrate reduced beyond nitrite. Ammonia from arginine produced both aerobically and anaerobically. Egg yolk always cleared and usually casein and gelatin hydrolysed; usually lipolytic to lard and butter. Tweens are hydrolysed by most strains. Growth occurs in the presence of $15 \%$ sodium chloride and usually at $10^{\circ}$ and $45^{\circ}$.

Subgroup II: essential characters. Phosphatase-positive and acetoin-positive, coagulase-negative and mannitol-negative.

Other characters. Acid from glycerol and maltose, usually from galactose and lactose, and sometimes from dextrin. Nitrate usually reduced beyond nitrite. Arginine usually only attacked aerobically with the release of ammonia. Usually caseinolytic, hydrolyse gelatin, and may also clear egg yolk. Lipolytic and usually hydrolyse Tweens. Generally poor growth in media with no added sodium chloride; no growth at $10^{\circ}$ but usually growth at $45^{\circ}$.

Subgroup III: essential characters. Phosphatase-positive, coagulase-negative; no acid from maltose or mannitol; acetoin-negative.

Other characters. Acid from glycerol and usually from lactose and galactose. 
Nitrate reduced beyond nitrite; ammonia from arginine. Casein and egg yolk are cleared and gelatin hydrolysed. Most strains are lipolytic and hydrolyse the lower Tweens. Poor growth in the presence of $15 \%$ sodium chloride; no growth at $10^{\circ}$ but usually growth at $45^{\circ}$.

Subgroup IV: essential characters. Acetoin-positive, phosphatase-, coagulase-, lactose- and mannitol-negative.

Other characters. Acid from glycerol and sometimes galactose. Some strains may form acid from maltose and hydrolyse fats and Tweens.

Subgroup $V$ : essential characters. Acetoin-positive, acid from lactose and maltose phosphatase- and coagulase-negative; no acid from mannitol.

Other characters. Acid from glycerol and sometimes from galactose. Nitrate usually reduced beyond nitrite. Casein usually cleared but egg yolk and gelatin not usually attacked. Butter and lard are hydrolysed, and usually Tweens. Many strains do not grow in the presence of $15 \%$ sodium chloride.

Subgroup VI: essential characters. Acetoin-positive; acid from mannitol (usually aerobic only), phosphatase- and coagulase-negative.

Other characters. Acid from glycerol and sometimes from galactose; aesculin may be hydrolysed. Strains differ as to ability to utilize lactose and maltose and by the use of these characters 3 types can be separated:

$\begin{array}{cccc}\text { Type } & \text { No. of isolates } & \text { Lactose } & \text { Maltose } \\ 1 & 12 & + & + \\ 2 & 68 & \pm & + \\ 3 & 16 & - & -\end{array}$

Most strains form ammonia in arginine broth and reduce nitrate to nitrite or a more reduced product. Many strains are inhibited by $15 \%$ sodium chloride; most grow at $45^{\circ}$ but not usually at $10^{\circ}$.

\section{Group 2. Micrococcus Cohn emend. Evans}

General characters. Variable sized $(0 \cdot 5-3 \cdot 0 \mu)$ Gram-positive and catalase-positive, cocci forming irregular clusters or tetrads. Acid from glucose, if at all, only aerobically.

Acetoin is produced by some strains; terminal pH value usually greater than $\mathbf{5}$ in $2 \%$ glucose broth. Most strains form acid from arabinose, glycerol, lactose, maltose, mannitol and xylose. Some form acid from cellobiose, dextrin, galactose, inositol, raffinose, rhamnose, salicin and starch. Aesculin is usually hydrolysed. Few strains are phosphatase-positive. Casein, egg yolk and gelatin are hydrolysed by some strains but generally only weakly. Fats and Tweens are hydrolysed by some strains. Nitrite is usually the end product of nitrate reduction. Some strains utilize ammonium phosphate as sole nitrogen source. Most grow in the presence of $15 \%$ sodium chloride and at $10^{\circ}$; usually no growth at $45^{\circ}$.

Subgroup 1: essential characters. Acetoin-positive. No acid from mannitol or lactose.

Other characters. Terminal pH value usually less than $\mathbf{5 \cdot 0}$ in glucose broth. Acid usually from glycerol, maltose and sometimes from xylose; aesculin hydrolysed by some strains. Casein and egg yolk may be cleared. Usually nitrate reduced to nitrite or a more reduced product. Some strains are lipolytic; Tweens are not usually 
hydrolysed. Most strains grow at $45^{\circ}$ but usually not at $10^{\circ}$; many are inhibited by $15 \%$ sodium chloride.

Subgroup 2 : essential characters. Acetoin-positive, acid from lactose and maltose.

Other characters. Acid from glycerol and galactose. Nitrate usually not reduced. Lipolytic but generally proteins only weakly attacked. Usually growth at $10^{\circ}$ but not at $45^{\circ}$.

Subgroup 3 : essential characters. Acetoin-positive, acid from maltose and mannitol.

Other characters. Acid from glycerol, usually from lactose and sometimes from galactose and xylose; aesculin hydrolysed by some strains. Three types can be recognized on the hydrolysis of lard and Tweens and ability to grow and form acid on a medium containing ammonium dihydrogen phosphate as sole nitrogen source.

\begin{tabular}{|c|c|c|c|c|}
\hline \multirow[b]{2}{*}{ Type } & \multirow{2}{*}{$\begin{array}{l}\text { No. of isolates } \\
\text { examined }\end{array}$} & \multicolumn{2}{|c|}{ Hydrolysis of } & \multirow{2}{*}{$\begin{array}{l}\text { Ammonium } \\
\text { phosphate } \\
\text { utilization }\end{array}$} \\
\hline & & Lard & Tweens & \\
\hline 1 & 28 & + & + & - \\
\hline 2 & 30 & + & - & + \\
\hline 3 & 17 & - & - & - \\
\hline
\end{tabular}

Subgroup 4: essential characters. Acetoin-positive; acid from arabinose.

Other characters. Acid from glycerol and mannitol and usually from lactose, maltose and xylose; sometimes from cellobiose, galactose and inositol. Aesculin usually hydrolysed. Nitrate reduced by most strains to nitrite. Proteins usually not attacked. Lard and Tweens not hydrolysed. Grows at $10^{\circ}$ but not usually at $45^{\circ}$. Some strains utilize ammonium phosphate.

Subgroup 5: essential characters. Acid aerobically from glucose; acetoin-negative.

Other characters. Acid from glycerol and usually from galactose, lactose, maltose, mannitol and xylose; sometimes from dextrin and cellobiose. Aesculin hydrolysed by most strains. Nitrate usually reduced to nitrite. Usually no hydrolysis of casein, egg yolk or fat; Tweens not hydrolysed. Usually growth at $10^{\circ}$ but not at $45^{\circ}$. Some strains grow and form acid in Hucker's ammonium phosphate medium.

Subgroup 6: essential characters. Phosphatase-positive; acid formed aerobically from glucose, arabinose and mannitol.

Other characters. Acetoin-negative; acid from galactose, glycerol, lactose, maltose, salicin and xylose and sometimes from cellobiose, raffinose and rhamnose. Tweens and fat hydrolysed. Growth at $10^{\circ}$ and sometimes at $45^{\circ}$.

Subgroup 7 : essential characters. Unable to form detectable amounts of acid from glucose in the described Hugh \& Leifson test (above).

Other characters. Usually large-celled irregular cocci or tetrad formers. Gelatin is usually hydrolysed and casein sometimes cleared. Some strains are actively lipolytic and hydrolyse Tweens. Most grow at $10^{\circ}$ and $45^{\circ}$ but are unable to grow in the presence of $15 \%$ sodium chloride.

I wish to thank Miss B. A. Smith for her valuable assistance. 


\section{REFERENCES}

Abd-El-Malek, Y. \& Gibson, T. (1948). Studies in the bacteriology of milk. II. The staphylococci and micrococci of milk. J. Dairy Res. 15, 249.

Ayers, H. S. \& RupP, P. (1922). Differentiation of haemolytic streptococi from human and bovine sources by the hydrolysis of sodium hippurate. J. infect. Dis. 30, 388.

Baird-Parker, A. C. (1962). An improved diagnostic and selective medium for isolating coagulase positive staphylococci. J. appl. Bact. 25, 12.

BARBER, M. \& Kuper, S. W. A. (1951). Identification of Staphylococcus pyogenes by the phosphatase reaction. J. Path. Bact. 63, 65.

Barnett, J. A., Ingram, M. \& Swain, T. (1956). The use of $\beta$-glucosides in classifying yeasts. J. gen. Microbiol. 15, 529 .

BarritT, M. M. (1936). The intensification of the Voges-Proskauer reaction by the addition of $\alpha$-naphthol. J. Path. Bact. 42, 441.

BatTY-Smith, C. G. (1941). The detection of acetyl-methyl-carbinol in bacterial cultures. A comparative study of the methods of O'Meara and of Barritt. J. Hyg., Camb. 41, 521.

Bergey's Manual of Determinative Bacteriology (1957). 7th ed., pp. 454 et seq. Ed. R. S. Breed, E. G. D. Murray \& N. R. Smith. London: Baillière, Tindall and Cox.

Carlquist, P. R. (1956). A biochemical test for separating paracolon groups. J. Bact. 71, 339.

CAvetT, J. J. (1962). The microbiology of vacuum packed sliced bacon. J. appl. Bact. (In the Press.)

Duthie, E. S. (1954). Evidence for two forms of staphylococcal coagulase. J. gen. Microbiol. 10, 427.

ECKFond, M. O. (1927). Measurement of diastatic action. Amer. J. Hyg. 7, 201.

Evans, J. B. (1947). Anaerobic fermentation of mannitol by staphylococci. J. Bact. 54, 266.

Evans, J. B. (1948). Studies of staphylococci with special reference to the coagulasepositive types. J. Bact. 55, 793.

Evans, J. B., Bradford, W. L. \& Niven, C. F. Jr. (1955). Comments concerning the taxonomy of the genera Micrococcus and Staphylococcus. Int. Bull. bact. Nomen. 5, 61.

Evans, J. B. \& Niven, C. F. Jr. (1950). A comparative study of known food poisoning staphylococci and related varieties. J. Bact. 59, 545.

Frazier, W. C. (1926). A method for detecting changes in gelatin due to bacteria. J. infect. Dis. 39, 302.

Garvie, E. J., Higgs, T. M. \& Neave, F. K. (1961). Unusual varieties of Staphylococcus aureus. J. Path. Bact. 81, 255.

Gibson, T. (1955). The principles of microbial classification. General morphology. J. gen. Microbiol. 12, 324.

Hastings, E. G. (1904). The action of various classes of bacteria on casein as shown by milk-agar plates. Zbl. Bakt., 2 Abt. Orig. $12,590$.

HrLl, L. R. (1959). The Adansonian classification of the staphylococci. J. gen. Microbiol. $20,277$.

Hucker, G. J. (1924). Studies on the Coccaceae. II. A study of the general characters of the micrococci. Tech. Bull. N.Y. St agric. Exp. Sta. no. 100.

HUGH, R. \& Leifson, E. (1953). The taxonomic significance of fermentation versus oxidative metabolism of carbohydrates by various gram negative bacteria. J. Bact. 66, 24 .

Hurst, A., StutTard, L. W. \& Woodroffe, R. C. S. (1960). Disinfectants for use in barsoaps. J. Hyg., Camb. 58, 159.

Jones, A. \& RicharDs, T. (1952). Nile Blue and Victoria Blue as indicators in lipolysis media. Proc. Soc. appl. Bact. 15, 82.

Judicial Commission of the International Committee of Bacteriological Nomenclature (1958). Int. Bull. bact. Nomen. 8, 138.

Lysenko, O. (1961). Pseudomonas-An attempt at a general classification. J. gen. Microbiol. 25, 379. 
Mackie and McCartney's Handbook of Bacteriology (1960). Ed. R. Cruickshank. Edinburgh: E. \& S. Livingstone Ltd.

Moeller, V. (1955). Simplified tests for some amino acid decarboxylases and for the arginine dihydrolase system. Acta path. microbiol. scand. 36, 158.

Mosser, D. A. A. (1962). An attempt of classification of the catalase positive cocci: staphylococci and micrococci. Bact. Proc. , 39.

OurTzki, A. L. (1954). Hydrogen sulphide production by non-multiplying organisms and its inhibition by antibiotics. J. gen. Microbiol. 11, 160.

PoнJA, M. S. (1960). Micrococci in fermented meat products. Classification and description of 171 different strains. Suom. Maataloust. Seur. Sulk, no. 96.

Shaw, C., Stitt, J. M. \& Cowan, S. T. (1951). Staphylococci and their classification. J. gen. Microbiol. 5, 1010.

SIERRA, G. (1957). A simple method for the detection of lipolytic activity of micro-organisms and some observations on the influence of contact between cells and fatty substrates. Antonie van Leeurwenhoek J. Serol. Microbiol. 23, 15.

SNeATh, P. H. A. (1957). The application of computers to taxonomy. J. gen. Microbiol. 17, 201.

Society of American Bacteriologists (1957). Manual of Microbiological Methods. New York: McGraw-Hill.

Thatcher, F. S. \& Simon, W. (1957). Some physiological and toxigenic properties of members of the genus Micrococcus in relation to taxonomy. Int. Bull. bact. Nomen. 7, 21.

Thornley, M. J. (1960). The differentiation of Pseudomonas from other Gram negative bacteria on the basis of arginine metabolism. J. appl. Bact. 23, 37. 